\title{
Glucose-6- Phosphate Dehydrogenase Activity in Newborn in Jos: A Necessary Evaluation for Icteric Neonates
}

\author{
Jatau $\mathrm{ED}^{1 *}$, Toma $\mathrm{BO}^{2}$, Egesie $\mathrm{OJ}^{1}$, Damulak OD ${ }^{1}$, Ayuba $\mathrm{Z}^{1}$, Ewuga $\mathrm{OJ}^{3}$, Ma'an VT. ${ }^{3}$ \\ ${ }^{I}$ Department of Haematology and Blood Transfusion, Jos University Teaching Hospital. \\ ${ }^{2}$ Department of Paediatrics, Jos University Teaching Hospital. \\ ${ }^{3}$ Department of Haematology and Blood Transfusion, Federal Medical Centre, Keffi.
}

*Corresponding Author: Jatau ED. Department of Haematology and Blood Transfusion, Jos University Teaching Hospital.Email: ezradjatau@gmail.com

\begin{abstract}
Red blood cell glucose-6-phosphate dehydrogenase (G6PD) is a key regulatory enzyme with the major role of meeting the cellular need for reductive biosynthesis and maintenance of redox status. G6PD deficiency is a common inherited enzyme defect associated with severe neonatal hyperbilirubinaemia that can result in permanent neurologic damage or death. This study was aimed at estimating the level of G6PD activity among icteric neonates to assess its usefulness in the evaluation of icteric neonates in Jos. One hundred and fifty icteric neonates (92 males and 58 females) whose parents consented were consecutively enrolled as they presented at the Special Care Baby Units (SCBU) of the Jos University Teaching Hospital (JUTH), Bingham University Teaching Hospital (BhUTH), and the Plateau State Specialist Hospital (PSSH), Jos. These subjects had their G6PD activity levels assayed using the Pointe Quantitative Diagnostic Kit (USA) while other relevant clinical information was obtained using a questionnaire. G6PD activity of the icteric neonates ranged between 0.54 and $24.18 \mathrm{IU} / \mathrm{gHb}$ with a mean of $8.02 \pm 4.87 \mathrm{IU} / \mathrm{gHb}$. Sixty-one ( $40.7 \%$ ), comprising 45 males and 16 female neonates were G6PD deficient with mean G6PD activity of $3.79 \pm 1.37 \mathrm{IU} / \mathrm{gHb}$ while eighty-nine $(59.3 \%)$ were G6PD normal with a mean G6PD activity of $10.92 \pm 4.24$ $\mathrm{IU} / \mathrm{gHb}$. G6PD activity in icteric neonates in Jos varies widely with a relatively high proportion of these neonates being G6PD deficient. Determination of G6PD activity in icteric neonates should therefore form an important evaluation tool for identification and intervention in those with the deficiency.
\end{abstract}

Keywords: Evaluation,Glucose-6-phosphatedehydrogenase,Icteric,Neonates

\section{INTRODUCTION}

G lucose-6-phosphate dehydrogenase (G6PD) is a cytoplasmic enzyme distributed in all cells and catalyses glucose-6-phosphate oxidation to 6phosphogluconolactone, converting the co-enzyme nicotinamide adenine dinucleotide phosphate (NADP) to its reduced form (NADPH). NADPH is required for reduction of oxidized glutathione (GSSG) to its reduced form (GSH) by glutathione reductase which helps protect the red blood cells from oxidative stress and reactive oxygen species. ${ }^{1}$ The red blood cell (RBC) is vulnerable to injury by exogenous and endogenous oxidants, G6PD enzyme deficiency or its impaired function, reduces the ability of the red blood cell to protect itself against oxidative injuries. ${ }^{1}$ This results in haemolytic anaemia of varying severity as well as neonatal hyperbilirubinaemia a major cause of neonatal morbidity and mortality. ${ }^{1,2}$ 
Glucose-6-phosphate dehydrogenase deficiency, an inherited $\mathrm{X}$-linked disorder is the most common of the red cell enzymes defect affecting about 400 million people globally with highest prevalence in the tropics, subtropics and in the Mediterranean countries. Migration has contributed to the worldwide distribution of G6PD deficiency with the prevalence varying among different ethnic groups. ${ }^{2}$ In Nigeria, the prevalence of G6PD deficiency ranges from 4$26 \%$ with the male population and icteric neonates having a prevalence of $20-26 \%$ and $20.5-35.3 \%$ respectively. ${ }^{3,4}$ It affects hemizygous males, homozygous females, about $10 \%$ of heterozygous females and those with Turner's syndrome ${ }^{5}$ The most significant manifestations of G6PD deficiency are drug-induced haemolysis, non-spherocytic haemolytic anaemia, favism, and neonatal hyperbilirubinaemia that is usually severe and prolonged with a tendency to developing brain damage, or death. ${ }^{5}$

Hyperbilirubinaemia in G6PD deficient neonates exposed to icterogenic agents occurs in association with many factors that include immaturity of their liver conjugating enzymes system, method of feeding, and neonatal sepsis. ${ }^{5,6}$ It is seldom associated with mortality when detected early however management of hyperbilirubinaemia remains a challenge for neonatal medicine in resource poor settings like ours. ${ }^{6,7}$ It is therefore necessary to assess the enzyme activity in the neonates so that those with the deficiency can be identified early and appropriate intervention instituted for better outcomes

\section{MATERIALS AND METHODS}

This cross-sectional study was carried out at the Special Care Baby Units of Jos University Teaching Hospital, Bingham University Teaching Hospital, and Plateau State Specialist Hospital, Jos between March 2013 and February 2014 following approval from the Human Research and Ethics Committees of these institutions. All Jaundiced neonates admitted into the SCBUs whose parents gave consent were enrolled excluding those with previous history of blood transfusion, cephalhaematomas, bleeding tendencies and asphyxia. Venous blood was taken into an EDTA and plain sample bottle for full blood count (FBC), G6PD enzyme assay, and bilirubin assay using standard laboratory procedures. G6PD enzyme assay was carried out using reagents and control samples manufactured by the Pointe Reagent Company (USA). Red blood cell G6PD enzyme activity $<6.0 \mathrm{IU} / \mathrm{gHb}$ was considered deficient.

\section{Statistical analysis}

Data was analyzed using EPI-info Version 6 software. Mean, median, mode and standard deviation (SD) were used to describe continuous data. Students' t-test was used to assess the significance between means of two groups. Chi-square was used to compare categorical data. Results were presented in tables and chart. $P$ value $\leq 0.05$ was considered statistically significant

\section{RESULTS}

One hundred and fifty icteric neonates comprising 92 (61.3\%) males and 58 (38.7\%) females $(\mathrm{M}: \mathrm{F}=1.6: 1)$ were studied. Their mean age at presentation was $3.28 \pm 3.11$ days. Majority, 133 (88.6\%) were aged between 0 and 5 days at presentation. (Fig1).

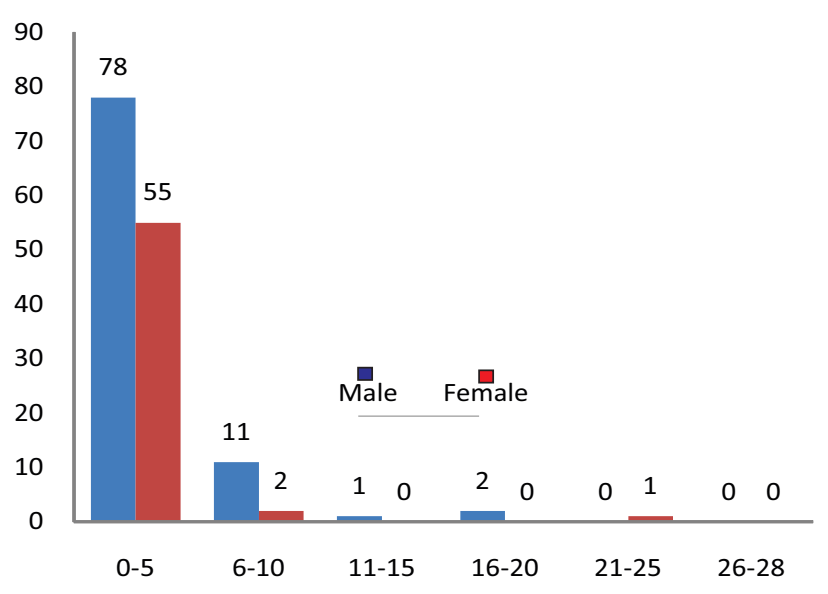

Figure 1: Age and sex distribution of neonates presenting with jaundice in tertiary health facilities in Jos between March 2013 and February2014

Laboratory parameters of the neonates showed a mean and median haemoglobin concentration of $15.90 \pm 2.23 \mathrm{~g} / \mathrm{dl}$ and $15.69 \mathrm{~g} / \mathrm{dl}$ respectively and a range of 11.33 to $22.30 \mathrm{~g} / \mathrm{dl}$ while the mean haematocrit was $0.47 \pm 0.06$, median 0.45 and a range of $0.34-0.67$. The mean serum bilirubin was $205.01 \pm$ $96.57 \mu \mathrm{mol} / \mathrm{L}$ with mode of $184.50 \mu \mathrm{mol} / \mathrm{L}$ and a range of 86.70 to $06.00 \mu \mathrm{mol} / \mathrm{L}$.(Table 1 ) 
Table 1- Relevant laboratory parameters of neonates presenting with jaundice in tertiary health facilities in Jos between March 2013 and February 2014 Parameters

$$
\text { n; (150) }
$$

\begin{tabular}{ll}
\hline Haemoglobin concentration $(\mathrm{g} / \mathrm{dl}$; mean $\pm \mathrm{SD})$ & $15.90 \pm 2.23$ \\
Haematocrit $($ mean $\pm \mathrm{SD})$ & $0.47 \pm 0.06$ \\
Serum bilirubin $(\mu \mathrm{mol} / \mathrm{L}$; mean $\pm \mathrm{SD})$ & $205.01 \pm 96.57$ \\
G6PD activity $(\mathrm{IU} / \mathrm{gHb}$; mean $+\mathrm{SD})$ & $8.02 \pm 4.87$ \\
\hline
\end{tabular}

G6PD activity ranged from $0.54-24.18 \mathrm{IU} / \mathrm{gHb}$ with a mean activity of 8.02 $\pm 4.87 \mathrm{IU} / \mathrm{gHb}$ and median of $7.19 \mathrm{IU} / \mathrm{gHb}$. Sixty-one (40.7\%) of them were G6PD deficient comprising 45 males and 16 females. Their mean G6PD activity was $3.53 \pm 1.34 \mathrm{IU} / \mathrm{gHb}$ and $4.53 \pm 1.18 \mathrm{IU} / \mathrm{gHb}$ respectively. There was a statistically significant difference between the mean G6PD activity of the male and female icteric neonates $(\mathrm{t}=2.64, \mathrm{P}=0.01)$ (Table 2$)$.

Table 2- G6PD activity and Sex of neonates presenting with jaundice in tertiary health facilities in Jos between March 2013 and February 2014

\begin{tabular}{|c|c|c|c|c|c|c|c|}
\hline \multicolumn{8}{|c|}{ Sex } \\
\hline \multicolumn{4}{|c|}{ Male } & \multicolumn{4}{|l|}{ Female } \\
\hline G6PD status & n $\quad(\%)$ & G6PD activity* & n $\quad(\%)$ & G6PD activity* & $\mathbf{t}$ & $\mathbf{P} \quad \mathrm{T}$ & Total \\
\hline G6PD deficient & $45(48.9)$ & $3.53 \pm 1.34$ & $16(27.6)$ & $4.53 \pm 1.18$ & 2.64 & 0.01 & 61 \\
\hline G6PD normal & $47(51.1)$ & $10.86 \pm 4.60$ & $42(72.4)$ & $10.91 \pm 3.86$ & 0.14 & 0.89 & 89 \\
\hline Total & $92(100)$ & & $58(100)$ & & & & 150 \\
\hline Parenthesis $=P e$ & ntage to & & an $\pm S D)$ & $/ g H b$ & & & \\
\hline
\end{tabular}

Twenty two (36.1\%) of the G6PD deficient neonates and $40(44.9 \%)$ of the G6PD normal neonates had mild hyperbilirubinaemia with a mean serum bilirubin of $132.3 \pm 24.6 \mu \mathrm{mol} / \mathrm{L}$ and $135.8 \pm 28.9 \mu \mathrm{mol} / \mathrm{L}$ respectively. Hyperbilirubinaemia in relation to G6PD status did not show any statistical significant difference, $\mathrm{P}>0.05$. (Table 3 )

Table 3- G6PD status and severity of hyper-bilirubinaemia of neonates presenting with jaundice in tertiary health facilities in Jos between March 2013 and February 2014

\section{G6PD status}

\begin{tabular}{lcccccccc}
\hline & \multicolumn{3}{c}{ Deficient } & \multicolumn{3}{c}{ Normal } \\
\hline Hyper-bilirubinaemia & $\mathbf{n}$ & $\%$ & mean SB & $\mathbf{n}$ & $\mathbf{\%}$ & mean SB & $\mathbf{t}$ & $\mathbf{P}$ \\
\hline Mild & 22 & 36.1 & $132.3 \pm 24.6$ & 40 & 44.9 & $135.8 \pm 28.9$ & 0.70 & 0.49 \\
Moderate & 24 & 39.3 & $205.6 \pm 26.6$ & 36 & 40.4 & $203.7 \pm 24.2$ & 0.29 & 0.78 \\
Severe & 15 & 24.6 & $383.1 \pm 110.1$ & 13 & 14.6 & $338.9 \pm 100.4$ & 1.10 & 0.28 \\
\hline Total & 61 & 100 & & 89 & 100 & & & \\
\hline
\end{tabular}

\section{DISCUSSION}

The mean G6PD activity of the icteric neonates in this study was $8.02 \pm 4.87 \mathrm{IU} / \mathrm{gHb}$ while that of deficient icteric neonates was $3.79 \pm 1.37 \mathrm{IU} / \mathrm{gHb}$. The proportion of neonates with G6PD deficiency was $40.7 \%$. Azma et al in Malaysia reported a mean G6PD activity of $12.43 \pm 2.28 \mathrm{IU} / \mathrm{gHb}$ (Normal; 10.15-14.71 IU/gHb) in neonates while Reclos et al in Greece had an average G6PD activity level of $10.6 \mathrm{IU} / \mathrm{gHb}$ (Normal; $\geq 6.4 \mathrm{IU} / \mathrm{gHb}$ ). ${ }^{7}$,

${ }^{8}$ These estimations were carried out using different G6PD assay kits and in different geographical locations which could have contributed to the variance in mean G6PD activity observed in this study.

The mean G6PD level of the deficient neonates in this study was higher than the finding of 1.50 $\pm 0.02 \mathrm{IU} / \mathrm{gHb}$ by Uko et al in Calabar. Similarly, Obasa et al in Ilorin while determining G6PD levels in babies delivered at University of Ilorin Teaching Hospital reported a normal value of $5.72 \pm 2.45 \mathrm{IU} / \mathrm{gHb}$ in females and $4.99 \pm 2.30 \mathrm{IU} / \mathrm{gHb}$ in males while babies with G6PD deficiency had comparable G6PD enzyme activities of $2.1 \pm$ 0.66 and $2.05 \pm 0.60 \mathrm{IU} / \mathrm{gHb}$ in males and females respectively. ${ }^{10}$ George et al in Port Harcourt, Nigeria, considered values below $40 \%$ of normal adult G6PD activity level (8.83 $\pm 1.59 \mathrm{IU} / \mathrm{gHb}$ ) as deficient. ${ }^{11}$

He reported a mean G6PD level for deficient Icteric newborns to be $17.3 \pm 10.9 \%$ with a G6PD deficiency prevalence of $52.5 \%$. In a study conducted in Brazil, G6PD activity $<2.0$ $\mathrm{IU} / \mathrm{gHb}$ was considered profound deficiency, 2.0-6.0 IU/gHb as partially deficient while activity of $>6.0 \mathrm{IU} / \mathrm{gHb}$ was termed normal. Prevalence of G6PD deficiency reported in the study in Brazil was 7.9\%. ${ }^{12}$ These findings are not surprising as it has been reported in Africa, South of the Sahara, that three different G6PD variants with polymorphic gene frequencies and activity exist. ${ }^{13}$ G6PD B is the commonest 
with normal enzyme activity followed by G6PD A ${ }^{+}$with $98 \%$ activity without association with haemolysis. ${ }^{13}$ The third variant G6PD A ${ }^{-}$with an activity of $20 \%$ is associated with haemolysis especially when the red cells are exposed to certain foods, chemicals or drugs. ${ }^{13}$ The difference in enzyme activity may be attributed to the G6PD enzyme variant amongst the ethnic population studied warranting variable reference ranges. This is corroborated by the report that in African populations, three different G6PD genotypes are recognised in males $\left(\mathrm{GdA}^{+}, \mathrm{GdB}\right.$ and $\left.\mathrm{GdA}^{-}\right)$whilst in females six genotypes are recognised $\left(\mathrm{GdB} / \mathrm{GdB}, \mathrm{GdA}^{+} / \mathrm{GdB}\right.$, $\mathrm{GdA}^{+} / \mathrm{GdA}^{+}, \mathrm{GdB} / \mathrm{GdA}^{-}, \mathrm{GdA}^{-} / \mathrm{GdA}^{-}$and $\left.\mathrm{GdA}^{+} / \mathrm{GdA}^{-}\right) .{ }^{13}$ Ademowo et al in a study in Nigeria, demonstrated that each of these genotypes expresses varying levels of enzyme activity ranging from $9.5 \pm 3.7 \mathrm{IU} / \mathrm{gHb}$ in $\mathrm{GdB}$ in males to $1.7 \pm 1.1 \mathrm{IU} / \mathrm{gHb}$ in $\mathrm{GdA}^{-} / \mathrm{GdA}^{-}$genotype in females. $^{13}$

The proportion of icteric neonates with G6PD deficiency in this study is similar to the finding in Zaria, North West and Ilorin, North Central Nigeria where Ahmed et al, and Amiwero et al reported a prevalence of $40 \%$ and $43 \%$ respectively. ${ }^{14,15}$ Prevalence of $47.7 \%$ was found in Oshogbo, South Western Nigeria by Akanni et al and a comparable prevalence of $32 \%$ and $30.2 \%$ in Egypt and India respectively. ${ }^{16-18}$ These findings are however lower than the prevalence of $62 \%$ found in Ibadan, South West Nigeria as reported by Dawodu et al. ${ }^{19}$ These varying figures may be connected to the study population known to have different genetic composition and cultural practices. ${ }^{19,}{ }^{20}$ This is supported by the prevalence rates of G6PD deficiency among the Jews with a rate of $30 \%$ to $60 \%$ and the Arab Muslims with rates of $1.8 \%$ to $8.5 \%$ though living together for centuries in the same environment, suffering the same epidemics of malaria stressors but different cultures and religion. ${ }^{21}$ Many geneticists believe that the varying prevalence of G6PD deficiency population is a reflection of adaptation to malarial environments but frequency of carrier individuals, race, cultures, consanguineous and inter-ethnic marriages may have altered this adaptive response to malaria resulting in this unexpected variation within the same environment or region. ${ }^{21,22} \mathrm{~A}$ further study using a larger sample size will serve to confirm this finding. Methods of enzyme assay and sensitivity of these methods may have also significantly contributed to these variations. ${ }^{23,}{ }^{24}$ There is therefore the need to identify an acceptable, comparable, most sensitive and most specific assay method that will guarantee the authenticity of every report irrespective of where it is produced.

The sex distribution of G6PD deficient icteric neonates in this study showed a male proportion of $48.9 \%$ while the females were $27.5 \%$ with an approximate male: female ratio (M: F) of 3:1 similar to a finding in Iraq and some other parts of the World. ${ }^{25,26}$ This thus reaffirmed the natural history of G6PD deficiency being an X-linked recessive disorder, affecting male hemizygotes and female homozygotes or hemizygotes due to Turners' syndrome and if the phenomenon of normal $\mathrm{X}$-chromosome inactivation occurs. ${ }^{27} \mathrm{~A}$ statistically significant difference between G6PD deficient males and females was observed in this study. The mean level of G6PD activity depicted a lower activity in the deficient males due to reduced enzyme activity in all the males' red blood cell population. This also supports the fact that in heterozygote G6PD deficient females, half of their red blood cell populations have normal enzyme activity with the other halfexpressing deficient enzyme activity. ${ }^{28}$

In comparing the severity of hyperbilirubinaemia and G6PD levels, this study showed no statistically significant difference. This observation is comparable with that of Iolascum et al and Ainoon et al who stated that the level of enzyme activity in G6PD deficient erythrocytes does not bear a consistent relationship to degree of hyperbilirubinaemia. ${ }^{29}$

${ }^{30}$ It is however contrasting with a report from Iran where maximum total serum bilirubin levels were significantly higher among G6PD deficient icteric neonates when compared with G6PD normal icteric neonates. ${ }^{31}$ Contrary to the statistical conclusion on the relationship between hyperbilirubinaemia and G6PD status in this study, hyperbilirubinaemia of varying severity that requires urgent attention was demonstrated. Other factors may have influence the bilirubin levels in both groups and the fact still remains that attention must be given to any neonate with serum bilirubin levels of the magnitude demonstrated in this study irrespective of their G6PD status. The G6PD deficient icteric neonates in this study had normal haemoglobin concentration and haematocrit without changes suggestive of haemolysis. This therefore concurs with the view that the predominant factor in the pathogenesis of neonatal hyperbilirubinaemia associated with G6PD deficiency might 
be decreased bilirubin conjugation due to promoter polymorphism for the gene encoding the bilirubin conjugation enzyme resulting in decrease bilirubin elimination. ${ }^{32,33}$ This finding may also be related to the possible predominant G6PD variant in our environment which may not be the haemolysis causing variant. ${ }^{34}$

\section{CONCLUSION}

The high proportion of icteric neonates with G6PD deficiency in this study calls for a policy on early screening of all neonates through assessing their G6PD activity irrespective of their icteric status. This will assist in early detection of neonates with this deficiency and those at risk of developing hyperbilirubinaemia with the aim of instituting interventional measures to prevent its complications. There is also a need to carry out a larger population studies at National level to assay the G6PD activity in all neonates, identify the different G6PD variants and determine the national prevalence in our population.

\section{Acknowledgement}

Our appreciation goes to the entire work force of the Special Care Baby Units of the Jos University Teaching Hospital, Bingham University Teaching Hospital, and Plateau State Specialist Hospital. We are grateful to Mr. Pius of the Trust Care Laboratory for allowing us access to his Spectrophotometer

\section{Conflict of Interest}

None declared.

\section{REFERENCES}

1. Beutler E. Glucose-6-phosphate dehydrogenase deficiency: A historical perspective. Blood 2008; 111: 16-24.

2. Kaplan M, Hammerman C. Glucose-6-phosphate dehydrogenase deficiency: A Worldwide Potential Cause of Severe Neonatal Hyperbilirubinaemia. NeoReviews 2000; 1: 32-39.

3. Egesie OJ, Joseph DE, Isiguzoro I, Egesie UG. Glucose-6-phosphate dehydrogenase (G6PD) activity and deficiency in a population of Nigerian males resident in Jos. Niger J Physiol Sci 2008; 23: 9-11.

4. Ogunfowora OB, Daniel OJ. Neonatal jaundice and its management: Knowledge, Attitude, and Practice of Community health workers in Nigeria. BMC Public Health 2006; 6: 19-25.
5. Liaqat A, Liaqat A. Glucose-6-phosphate dehydrogenase deficiency in Jaundiced Neonates. J P M I 2010; 24: 122-126.

6. Dallol A, Banni H, Gari MA, Al-Qahtani MH, Abuzenadeh AM, Al-Sayes F, et al. Five novel Glucose-6-Phosphate Dehydrogenase Deficiency Haplotypes Correlating with Disease Severity. Journal of Translational Medicine 2012; 10: 199-207.

7. Azma RZ, Hidayata N, Farisah NR, Hanidah NH, Ainoon O. Glucose-6-phosphate dehydrogenase enzyme activity in normal term neonates and adults using OSMMR 2000-D kit with Hb-Normalization. Southeast Asian J Trop Med Public Health 2010; 41: 982-988.

8. Reclos GJ, Hatzidakis CJ, Schulpis KH. Glucose-6phosphate dehydrogenase deficiency neonatal screening: Preliminary evidence that a high percentage of partially deficient female neonates are missed during routine screening. J Med Screen 2000; 7: 46-53.

9. Uko EK, Agwunobi SN, Udoh JJ. Glucose-6phosphate dehydrogenase levels in jaundiced neonates in Calabar. Niger J Med 2003; 12: 98-102.

10. Obasa TO, Mokuolu OA, Ojuawo A. Glucose-6phosphate dehydrogenase levels in babies delivered at the University of Ilorin teaching hospital. Nig J Paediatr 2011; 38: 165-169.

11. George IO, Akani NA. Evaluation of Glucose-6phosphate dehydrogenase deficiency in icteric newborns in Nigeria. Am J Trop Med Pub Health 2011; 1: 73-78.

12. Simone C, Raquel W, Vivian D, Volnei T, Roberto G. Prevalence of G6PD deficiency in newborns in the South of Brazil. J Med Screen 2006; 13: 85-86.

13. Ademowo OG, Falusi AG. Molecular epidemiology and activity of erythrocyte G6PD variants in a homogenous Nigerian population. East Afr Med J 2002; 79: 42-44.

14. Ahmed H, Yakubu AM, Hendrickse RG. Neonatal Jaundice in Zaria, Nigeria: A Second Prospective Study. Ann Trop Paediatr 1995; 1: 15-23.

15. Amiwero CE, Olatunji PO. Prevalence of G6PD Deficiency in Children Presenting with Jaundice in Ilorin, Nigeria. Int J Biomed \&HlthSci 2012; 8: 21-26.

16. Akanni EO, Oseni BSA, Agbona VO, Tijani BA, Tosan E, Fakunle EE, et al. Glucose-6-phosphate dehydrogenase deficiency in blood donors and jaundiced neonates in Oshogbo, Nigeria. J Med Lab Diagn2010; 1: 1-4.

17. Amal AE, Nawal MK, Seham AA, Manal AF, Azza KA. Prevalence of Glucose-6-Phosphate Dehydrogenase Deficiency in Jaundiced Neonates in Egypt. Aust J of Basic and ApplSci 2009; 3: 20162023.

18. Pao M, Kulkarn A, Gupta V. Neonatal screening for G6PD Deficiency. Indian J Paediat 2005; 72: 835-837.

19. Dawodu AH, Owa JA, Familusi JB. A Prospective 
Study of the Role of Bacterial Infection and G6PD Deficiency in Severe Neonatal Jaundice in Nigeria. Trop Geogr Med 1984; 36: 127-132.

20. Rahim F, Zahid S, Mukhtiar SAS, Said H, Uzair M. Glucose-6-Phosphate Dehydrogenase Deficiency in Neonates Presenting with Jaundice. J Postgrad Med Inst 2008; 22: 102-106.

21. Cartwright-Jones C. Henna and the Evil Eye, Salt and Demons, and the Geography of G6PD Deficiency. PhD Thesis, Geography Department, Kent State University 2008: 1-20.

22. Howes ER, Battle KE, Satyagraha AW, Baird JK, Hay SI. G6PD Deficiency: Global Distribution, Genetic Variants, and Primaquine Therapy. Advances in Parasitology 2013; 81: 135-169.

23. Minucci A, Giardina B, Zuppi C, Capoluongo E. Glucose-6-phosphate Dehydrogenase Laboratory Assay: How, When, and Why? IUBMB Life 2009; 61: 27-34.

24. Wong FL, Boo NY, Ainoon O, Wang MK. Comparison of detection of Glucose-6-Phosphate Dehydrogenase Deficiency using fluorescent spot test, enzyme assay and molecular method for prediction of severe neonatal hyperbilirubinaemia. Singapore Med J 2009; 50: 62-67.

25. Al-Hiali SJ. Glucose-6-Phosphate Dehydrogenase Deficiency among Neonates with Hyperbilirubinaemia in Western Iraq. J Fac Med Baghdad 2008; 50: 431434.

26. Anwar ZJ, Shahzada BZ, Samreen Ahmad. Frequency of G6PD Deficiency and its Severity in Neonatal Jaundice in Rehman Medical Institute, Peshawar. Khyber Med Univ J 2013; 5: 36-39.

27. Moiz B, Nasir A, Khan SA, Kherani SA, Qadir M. Neonatal Hyperbilirubinaemia in infants with G6PD c.563C > T Variant. BMC Pediatrics 2012; 12: 126133.

28. Jarullah J, Aljaouni S, Sharma MC, Bushra MSJ, Kamal MA. Detection of Glucose-6- phosphate dehydrogenase deficiency in Heterozygous Saudi Female Neonates. EnzEng 2012; 1: 105-107.

29. Iolascum A, Faienza MF, Perrota S. Gilbert Syndrome and Jaundice In Glucose-6-Phosphate Dehydrogenase Deficient Neonates. Haematologica 1999; 84: 99-102.

30. Ainoon A, Alawiyah A, Yu YH, Cheong SK. Semi quantitative Screening Test for G6PD Deficiency: Detects Severe Deficiency but misses a Substantial Proportion of Partially-Deficient Females. South East Asian J Trop Med Public Health 2003; 34: 405-414.

31. Iranpour R, Hashemipour M, Talaei SM, Soroshnia M, Amini A. Newborn Screening for Glucose-6-Phosphate Dehydrogenase in Isfahan, Iran: a quantitative assay. J Med Screen 2008; 15: 62-64.

32. Kawade N, Onishi S. The prenatal and Postnatal Development of UDP-glucuronylTransferase Activity towards Bilirubin and The Effect of Premature Birth on this Activity in the Human Liver. Biochem J 1981; 196:
257-260.

33. Kaplan M, Levy-Lahad E, Hammerman C, Lahad A, Beutler E. Gilberts syndrome and Glucose-6-phosphate dehydrogenase deficiency: A dose-dependent genetic interaction crucial to neonatal hyperbilirubinaemia. ProctNatlAcadSci USA 1997; 94: 12128-12132.

34. Obasa TO, Adesiyun OO, Mokuolu OA, Ojuawo AI. Comparative analysis of Glucose-6-phosphate dehydrogenase levels in preterm and term babies delivered at University of Ilorin Teaching Hospital. Paediatric Reports 2012; 4: 21-24. 